\title{
A Model for Pricing the License of Brand-Name Drugs Using Cooperative Game Theory
}

\author{
Amirhossein Mostofi ${ }^{1}$, Vipul Jain, Yi Mei
}

\begin{abstract}
This study examines the license valuation process of brand-name drugs using cooperative game theory. Brand-name drugs are non-generic and patented products which are produced by a domestic company licensed by the main manufacturer. To achieve the study aims, first, the pricing process of drugs in the local market is briefly described, and then, the benefits of cooperation between the foreign company and domestic company and local government are explained to show how these benefits can be presented as a licensing contract in the valuation process. Also, the advantages of licensing are described by implementing the proposed model on a sample problem. Furthermore, the factors that risk this valuation are presented by analyzing the sensitivity of the parameters of the problem. The Nash bargaining solution is also borrowed in this paper so as to consider the bargaining power of the alliance members. Our results showed that the assumption of equal negotiation power distorts the results from the common royalty rate, but when more bargaining power is considered for the government, as the legislator, the results of the proposed mechanism more resemble the conventional approaches.
\end{abstract}

Keywords: Brand-Name Drugs, License Valuation, Cooperative Game Theory, Nash Bargaining Solution.

\section{Introduction}

The supply chain paradigm has changed the individual behavior of organizations toward a cooperative and coordinated one. The supply chain managers consider all operations of the members and decide in a way that the performance of the supply chain is optimized. This does not mean that all members will be benefited from the integrated decisions of the supply chain. Therefore, some mechanisms are needed to provide enough incentives for the members by allocating them appropriate amount of the supply chain profit. This allocation is such that the income of members after the allocation is at least equal to their income when they operate independently. The integration and cooperation of the supply chain has been the main subject in the studies related to supply chain in recent years. In the present paper, the same subject is investigated in the context of the pharmaceutical supply chain (PSC).

The general PSC in this study includes the following components: primary manufacturer, secondary manufacturer, distribution centers, and retail outlets including pharmacies and hospitals. Figure (1) illustrates a general pharmaceutical network. The primary manufacturers produce the active ingredients, which are the chemical and molecular components of the medicine. Each stage of the production (quality control, changeover, cleaning, etc.) in such a manufacturer takes a long time, which is the intrinsic characteristic of production in primary manufacturers. Secondary manufacturers mix excipients and active gradient composition; then they produce, package, and control the quality of drugs. Through obtaining the necessary permissions, distribution companies usually have a significant role in marketing the products. These companies are an integral part of the supply chain. Moreover, based on the purposes of a pharmaceutical supply chain management, other players such as Drug Inspection Laboratories (DIL) (Imran et al., 2018), Managed Care Organization (MCO), Healthcare Maintenance Organization (HMO) (Shah, 2004), and other governmental or administrative bodies could be included in pharmaceutical supply chain management; also, they are usually concerned with the quality issues or quality control process.

\footnotetext{
${ }^{1}$ Amirhossein Mostofi (e-mail: amirhossein.mostofi@vuw.ac.nz)

School of Management, Victoria Business School, Victoria University of Wellington, New Zealand
} 


\section{IJCIEOM}

International Joint Conference on Industrial Engineering and Operations Management- ABEPRO-ADINGOR-IISE-AIMASEM (IJCIEOM 2020)

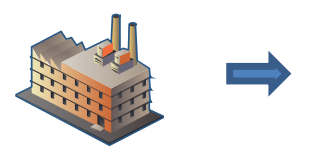

Primary Manufacturer

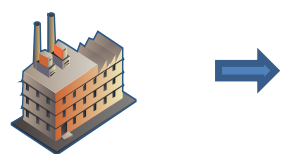

Secondary Manufacturer

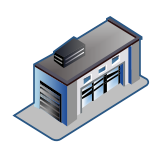

Distributors

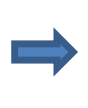

Fig 1. A general pharmaceutical supply chain

The health systems are characterized by high expenditure, high research and development costs, highly regulated structure, limited competition, and dominance of patient needs as one of the most basic human rights. PSC accounts for a significant amount of health system costs. In this regard, drugs have been reported to form about $9.8 \%$ of all national healthcare expenditures in 2014 (National Center for Health, 2016). Moreover, due to the importance of the health system, governments in almost all countries, regardless of their income level, pay considerable attention to this sector of the society and afford most of the medical costs through public insurances or other reimbursement schemes (Vogler and Martikainen, 2015). Such trends reveal the desirability of the government in controlling and reducing the health system cost. It could establish an alliance with other players of PSC and benefit from the resulting synergy of the cooperation. Doing so, the government could grant the rights and permissions of exclusive products to the producers and distributor of PSC, and other members discount the government by supplying the drugs at a lower price than the common market price. All the PSC members, including the government, could improve their performance by engaging in such a strategy. Considering such a cooperation between the PSC members, we use the cooperative game theory to study the pricing problem of the expensive drugs. The pricing scheme, as explained later, will be such that the profit of the government in the reduction of patient cost is in balance with the profit of the producers for supplying noteworthy amounts of the exclusive drugs in the local market. However, as expected, the bargaining power of the government against that of the producers could result in price reduction and request more discount on the market price. To take into account the bargaining power of the alliance members, the Nash bargaining solution is borrowed in this paper.

Also, it should be pointed out that the proposed methodology is not a mere pricing method, but it just modifies the current market price in a way that the competitive advantages of partners could be taken into account. It could be regarded as a discounting scheme which provides adequate motivations for partners to operate in a participatory style. Therefore, the mechanism is not to be claimed to be competitive with another pricing method, and it does not neglect the remarkable hypotheses hidden in the represented price of drugs. The possibility of using discount for offering lower prices has already been mentioned in other papers such as the study by (Csanádi et al., 2018).

Another important subject regarding the possibility of domestic production of brand drugs is the value of the license. Granting the formulas of the brand drugs entails an especial payment to the secondary manufacturer, which owns the formulas. Such a payment is usually arranged in the form of a license contract. The license contract needs the involvement of another coalition between the domestic manufacture and the secondary (foreign) manufacturer. This extends the analysis of the game from one coalition to two coalitions. The first coalition is established between the domestic and the secondary manufacturers to determine the value of the license contract parameters, and also to form the cooperative firm.

On the other hand, in the second coalition, the government and the cooperative firm negotiate about the new price of the drugs after granting the exclusive right of the production by the government to the cooperative firm. In this paper, exclusive domestic production of licensed-brand drugs; as a result of forming a cooperative firm by a domestic manufacturer and a foreign licensor; is studied as a cooperative strategy that could reduce the franchises related costs of the government. This strategy could provide many advantages for the government and the manufacturers among them, the increase in the income of the manufacturer are studied in this paper. For this benefit, the government also expects discounts from the cooperative firm and the value of the discount depends on the bargaining power of the government and the firm 


\section{IJCIEOM}

International Joint Conference on Industrial Engineering and Operations Management- ABEPRO-ADINGOR-IISE-AIMASEM (IJCIEOM 2020)

Although the problem of each coalition is discussed separately between the related partners of each coalition, those problems are not distinct, and as shown in this paper, they should be studied in an integrated and dependent framework. This kind of analysis is the novelty of the current study, which besides the embedded logic of the cooperative benefits and the requirement for representing discounted price, provides an integrated and supportive framework for decision making and addressing the pricing and license valuation problem in the considered alliance.

\section{$2 \quad$ Literature Review}

In the context of PSC, the coordination mechanisms and contracts have been mostly studied in recent years. Two new coordination mechanisms, namely economic and social collaborative models, were proposed by (Nematollahi et al., 2017) in a PSC, including one retailer and one supplier. Their proposed model aimed to determine the visit interval of the supplier and the service level of the retailer in two ways as follows:

1. Economic collaborative: maximizing the profit of PSC as a whole while ensuring minimum payoff (decentralized payoff) for all members.

2. Social collaborative: assuming that managers will provide sufficient compensations, though the decision making is done in such a way that the social welfare of the patient is maximized.

(Taleizadeh et al., 2019) studied a reverse PSC, in which the appropriate return prices could encourage the customers to resell the unexpired and useless drugs to the manufacturer. This initiative not only saves the environment from disposal damages of the drugs but also provides additional income to the manufacturer by selling the returned drugs again at a reduced price. An almost similar problem was reported by(Weraikat et al., 2016) when a 3PL was responsible for gathering the returned drugs. Revenue sharing was the coordination contract of that PSC. (Khodabakhshi et al., 2019) coordinated a three-echelon supply chain comprising a manufacturer, distributor, and retailer with two coordination contracts, namely spanning and pair-wise revenue-sharing contracts. In that paper, the demand was a function of the retail price and the Corporate Social Responsibility (CSR) level. (Hosseini-Motlagh et al., 2019) investigated a two-level PSC within it; a manufacturer was in charge of CSR investment and a retailer who faced with a stochastic and scenario-based demand identified the retail price and order quantity of drugs. The problem was solved in two states of centralized decision making and decentralized one. Next, an adjustable bi-level wholesale contract was proposed as the coordination mechanism, which aligns the members toward the centralized decisions while it provides adequate advantages for both the retailer and manufacturer than the decentralized decision-making manner.

(Jabarzare and Rasti-Barzoki, 2019) studied the problem of price and quality setting in a supply chain comprising a manufacturer and packaging company. The problem was evaluated in three ways: noncooperative game, cooperative game under revenue sharing contract, and cooperative game through profitsharing contract. Their results highlighted the increase in the utility of the customers, especially in the case of profit-sharing contract. The license contract assessed in this paper could be regarded as a coordinated contract, which provides the context for productive and profitable partnerships. In the PSC, the license contracts in various forms are a mediator for inter-firm partnerships. For example, in order to establish an alliance between a start-up firm and large pharmaceutical companies, (Yoon et al., 2018) distinguished three types of the license contract, namely milestone and optional upfront payment, royalty and optional upfront payment, and acquisition contract. They characterized the optimal arrangement for each contract and presented insights about the benefits each contract type suggests for start-ups and large pharmaceutical companies.

The mentioned studies reveal some facts about coordination issues in PCS, though they do not address many challenges in this area. They show the appropriateness of cooperative game theory for making decision about coordination problems. Furthermore, they highlight the importance and the need for coordination mechanisms in this context. Although the reviewed studies are mainly based on the cooperative game theory, they differ from the current study in terms of the actors and the type of participation. However, the proposed methodology is in line with the studies which consider different pricing mechanisms in PSC in contrast to current market trends; it also suggests the modifications of prices as the results of partnership and the advantages such partnership bear for the PSC as a whole. 


\section{IJCIEOM}

International Joint Conference on Industrial Engineering and Operations Management- ABEPRO-ADINGOR-IISE-AIMASEM (IJCIEOM 2020)

\section{The Proposed Model}

In our proposed model, we assume that a domestic company is negotiating with a brand-name drug manufacturer over a license and establishing a domestic company. Given the incentives provided by the local government for such an investment, the establishment of this company can have significant benefits to the partners, and the license fee can be modeled using cooperative game theory and considering the benefits of the project. Before describing the model in detail, the model assumptions are presented as follows:

1. Given the fact that the process of registering drugs in the local market and obtaining the needed licenses is time-consuming, it is presumed that the selected brand-name drug is a well-recognized product in the local market.

2. The pricing process of drugs varies around the world, and it is determined by the policies posed by local governments. In the present study, the pricing mechanism that specifies the sales revenue of a company is by the local pricing process.

3. Although there are several operational benefits for establishing a licensed company in the domestic market, the present study merely considers the benefits of this program in reducing transaction costs (tariffs and other import costs) and increasing market share for partners. Other benefits, such as having better production plans rather than importing products and the availability of sufficient drugs, are left untouched; future studies need to account for such issues.

4. In the present study, the planning horizon is considered to be equal to the remaining lifespan of the patent. In fact, after this time horizon, the formulation of the drug is introduced as generic, and no licensing right is preserved for the company. Also, we measure the company's final value in the time horizon equal to the value of a generic company and through considering the remaining life of the equipment.

5. As it was mentioned, local governments usually facilitate the cooperation of foreign companies with domestic ones to support Gross Domestic Product (GDP). Such facilities include tariff cuts for importing pharmaceutical raw materials and canceling the import of other brands in case of domestic production.

Considering the above assumptions, various aspects of the problem are mentioned in different parts of the study, and then the final model is presented.

\subsection{Drug Pricing and Demand}

The pricing mechanism of brand-name drugs varies in different countries. For example, while Germany has a free pricing method for these drugs, this free pricing method is controlled by the profit of the manufacturing companies in the UK. In other countries such as France, Turkey, Spain, and Iran, a fixed pricing mechanism is conducted along with comparing the prices with a number of reference countries and reviewing them over a specific period. According to the principles of fixed pricing, the prices of brandname drugs are compared in reference countries, including Australia, Greece, Spain, Portugal, Turkey, and the drug manufacturer country itself; then, the lowest price available in these countries is considered as the basis for pricing. After importing the drugs, customs tariffs and regular taxes are imposed (20-35\% for brand-name drugs), and then a profit margin up to $15 \%$ is considered for the importer. The profit margin of pharmacies for domestic products is $20-26 \%$, and for products used in hospitals or imported drugs is 15$20 \%$. Moreover, the profit margin of distributors is $50 \%$ of the profit margin of pharmacies, and this rate can be increased up to $20 \%$ for cold-chain drugs and narcotic analgesics. Most governments and insurance companies prefer generic drugs to brand-name ones. Since insurance companies usually refuse to cover brand-name drugs, the demand for these drugs is at the lowest level possible. However, if some brand-name drugs are prescribed for chronic and special diseases (e.g., Rebif for MS patients), some supporting organizations might allocate funds for these drugs and increase the demand for them. Therefore, the function of demand can be considered as a function of the price with low sensitivity.

Since the pricing of drugs is a non-competitive process determined by government organizations, the impact of discounts induced by price reductions on the demand and profitability of the company can be examined. 


\section{IJCIEOM}

International Joint Conference on Industrial Engineering and Operations Management- ABEPRO-ADINGOR-IISE-AIMASEM (IJCIEOM 2020)

\subsection{Deterministic Model}

As explained, creating a licensed company to produce a brand-name drug, at first, involves a coalition consisting of a foreign company with a drug patent and a domestic company as an investor. The local government, as the third player outside the alliance of these two companies, acts as a financial facilitator through paying the discrepancy of drug prices and franchise received from patients. Also, the local government plays a direct role in determining the price of the drug, and it can provide incentives for both parties to participate more actively, especially the foreign company. Considering that the newly established company is responsible for supplying the demand, we consider the capacity for establishing the company to be equal to its annual demand.

Assuming that the company's sales price to suppliers is equal to $p C$ and the annual demand is equal to $\mathrm{q}$, then the domestic company's sales revenue will be equal to $p C$.q. Taking into account the cost of production variable equal to $c L$ and the annual depreciation of the company equal to DPL, the operating profit excluding deductions of tax and license fee can be shown using the following equation:

$$
\pi=\left(p_{C}-c_{L}\right) \cdot q-D P_{L}
$$

Furthermore, the foreign company grants permission to the domestic company through a licensing contract to use its patented product. The most common form of licensing contracts is determined by considering the fixed amount of lump-sum amount (L) and a royalty percentage relative to sales (r). Hence, the foreign company's licensing payoff (LP) can be shown as:

$$
L P=L+r \cdot p_{C} \cdot q
$$

Now, considering the income tax of the domestic company equal to $\tau_{L}$ and the licensing revenue of the foreign company equal to $\tau_{F, 1}$, the revenue function of the domestic company $\left(\pi_{L, C}\right)$ and foreign company $\left(\pi_{F, C}\right)$ is determined by the establishment of the manufacturing company using the following equations:

$$
\begin{aligned}
& \pi_{L, C}=\left(1-\tau_{L}\right)\left(\left(p_{C}-c_{L}\right) \cdot q-D P_{L}-L-r \cdot p_{C} \cdot q\right) \\
& \pi_{F, C}=\left(1-\tau_{F}\right) \cdot L P=\left(1-\tau_{F}\right) \cdot\left(L+r \cdot q \cdot p_{C}\right)
\end{aligned}
$$

To determine the revenue function of the government as the third player after establishing the company, by government regulations, we assume that the drug under consideration has $\mathrm{x}$ percent of franchise paid by the consumers and the rest of this money is subsidized to the pharmacies. Considering the profit margin of pharmacies as $p s$ and the profit margin of distributors as ds percent of the profit margin of pharmacies, we can calculate the revenue function of the government as:

$$
\pi_{G, C}=-(1-x) \cdot(1+p s \cdot(1+d s)) \cdot p_{C} \cdot q
$$

It should be noted that in Eq. (5), government revenue has been represented with a minus sign because the government only covers the cost of patients using the received taxes or other revenues.

\subsection{The Joint Venture Bargaining Model}

In the present study, Nash's model of bargaining is used to model the determination of market price, partners' revenue, and analysis of different situations governing the problem. Now, we have two coalitions: the first is the partnership of the domestic company as an investor with the foreign company owning the license, and the second one is the coalition between the newly established company and the government, which plays the role of coalition pricing. In each coalition, given the bargaining power of the partners, we can have specific outcomes. 


\section{IJCIEOM}

International Joint Conference on Industrial Engineering and Operations Management- ABEPRO-ADINGOR-IISE-AIMASEM (IJCIEOM 2020)

\section{Discussion}

In this section, we implement the proposed methodology for pricing a licensed drug for the treatment of thalassemia patients in Iran. Thalassemia is caused by the low level of alpha and beta proteins in red blood cells. Hemoglobin is a component of red blood cells that carries oxygen throughout the body and produces alpha and beta proteins. In thalassemia patients, hemoglobin is not able to produce these proteins sufficiently. The patients are categorized into several classes based on the deficiency of each protein and its severity. Thalassemia is not fully curable, and the related drugs only reduce the symptoms and prevent the progression of the disease. Therefore, these patients have to deal with the disease throughout their lives. The best treatment for this disease is blood transfusion, but the adverse effect of this treatment is transfusion-induced iron overload in the patient's body (since there is no way for removing iron from the body). So, thalassemia patients have to use drugs to reduce iron levels in their blood. Jadenu ${ }^{\circledR}$ (deferasirox) is one of the newly developed drugs for this purpose and is produced under the license of Novartis. The supports provided by the government facilitated the insurance coverage of treatment costs by 85 percent $(\mathrm{X}=0.15)$. The patients pay the remaining 15 percent of the cost. Although the market penetration of the new drug $($ Jadenu ()$)$ is only 5 percent, regarding its proved effectiveness and the establishment of domestic manufacturing, it seems that the new drug will take 100 percent of the market soon. The annual depreciation rate for the foreign manufacturer is calculated. There are about 18,500 thalassemia patients in Iran who take medical drugs. The results for each supply chain member before and after cooperation are presented in Table 1.

Table 1. The results of revenue distribution (USD) in equal sharing mode

\begin{tabular}{|c|c|c|c|}
\hline $\begin{array}{c}\text { Supply chain } \\
\text { member }\end{array}$ & $\begin{array}{c}\text { The profit before } \\
\text { cooperation }\end{array}$ & $\begin{array}{c}\text { The profit of } \\
\text { cooperation }\end{array}$ & $\begin{array}{c}\text { The extra profit of } \\
\text { cooperation }\end{array}$ \\
\hline F & 4021875 & 17052948 & $\mathbf{1 3 0 3 1 0 7 3}$ \\
\hline L & 25760000 & 38791073 & $\mathbf{1 3 0 3 1 0 7 3}$ \\
\hline G & -207612075 & -181549928.9 & $\mathbf{2 6 0 6 2 1 4 6 . 1}$ \\
\hline \multicolumn{3}{|c|}{} & $\mathbf{5 2 1 2 4 2 9 2 . 1}$ \\
\hline
\end{tabular}

(Zaharoff, 2004) reported the average royalty fee in the pharmaceutical industry as $8 \%$, which is a significant difference from $14 \%$. This difference could be due to the equality of bargaining power for all players. As witnessed in the above case, the sales monopoly makes the profits of both foreign and domestic producers more than doubled compared to the pre-cooperation stage. Thus, even if the profit rates of both domestic and foreign producers are decreased compared to the equal sharing mode, they will probably have the motivation to cooperate. The government attempts to mainly satisfy the needs of patients rather than making self-profit or satisfying other members. Therefore, it can use its bargaining power to reduce the costs borne by patients by reducing the profits of all members. So, in the next section, we assume that the government's bargaining power is twice stronger than that of the coalition of domestic and foreign companies. Hence, we put $\mathrm{u}=0.66$ for this new state. Also, the equilibrium price for each gram of medicine and royalty fee is calculated as USD 108 and 11.8 percent, respectively. The license value for each gram of the medicine according to the new value of (r) is calculated as USD 12.74, which is much closer to the value obtained from 25 percent rule. Table 2 presents the revenues of each player in this new state.

Table 2. Results of revenue distribution (USD) after considering a doubled bargaining power for the government compared to that of the alliance of domestic and foreign companies

\begin{tabular}{|c|c|c|c|}
\hline $\begin{array}{c}\text { Supply chain } \\
\text { member }\end{array}$ & $\begin{array}{c}\text { The profit before } \\
\text { cooperation }\end{array}$ & $\begin{array}{c}\text { The profit of } \\
\text { cooperation }\end{array}$ & $\begin{array}{c}\text { The extra profit of } \\
\text { cooperation }\end{array}$ \\
\hline F & 4021875 & 13445965 & $\mathbf{9 4 2 4 0 9 0}$ \\
\hline L & 25760000 & 35184090 & $\mathbf{9 4 2 4 0 9 0}$ \\
\hline G & -207612075 & -171024428.4 & $\mathbf{3 6 5 8 7 6 4 6 . 6}$ \\
\hline \multicolumn{3}{|c}{ Sum } \\
\hline \multicolumn{3}{|c}{} \\
\hline \multicolumn{3}{|c|}{} \\
\hline
\end{tabular}




\section{IJCIEOM}

International Joint Conference on Industrial Engineering and Operations Management- ABEPRO-ADINGOR-IISE-AIMASEM (IJCIEOM 2020)

\subsection{Bargaining Power of Partners}

In many real-world issues, organizations or companies have different competitive advantages that result in their higher bargaining power. In the present study, the bargaining power of the partners was calculated through using the Nash bargaining model. First, the change in the bargaining power of the government against a coalition of domestic and foreign companies is evaluated.

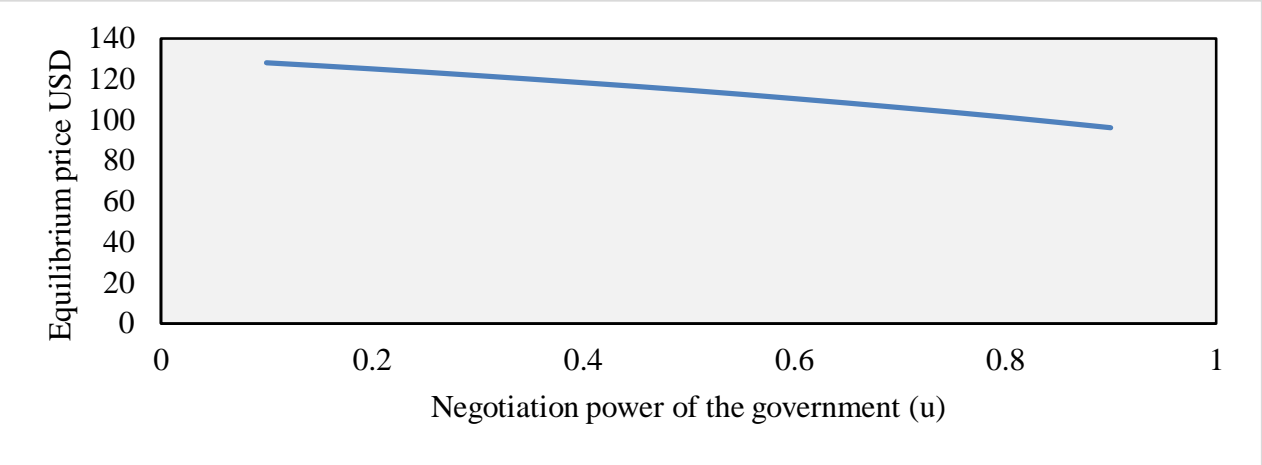

Fig 2. Changes in equilibrium price in relation to bargaining power of the government

Considering Figure 2, it can be observed that when the bargaining power of the government increases, the cost of domestically produced drugs decreases, government spending decreases, and the profits of both the domestic and foreign companies decrease. Indeed, the government is expected to use its bargaining power to reduce its service costs and patients' medical costs ultimately; and this can improve patients' well-being. Finally, the change in the bargaining power of the domestic company against the foreign company (v) is evaluated. The results of this evaluation are summarized in Figure 3.

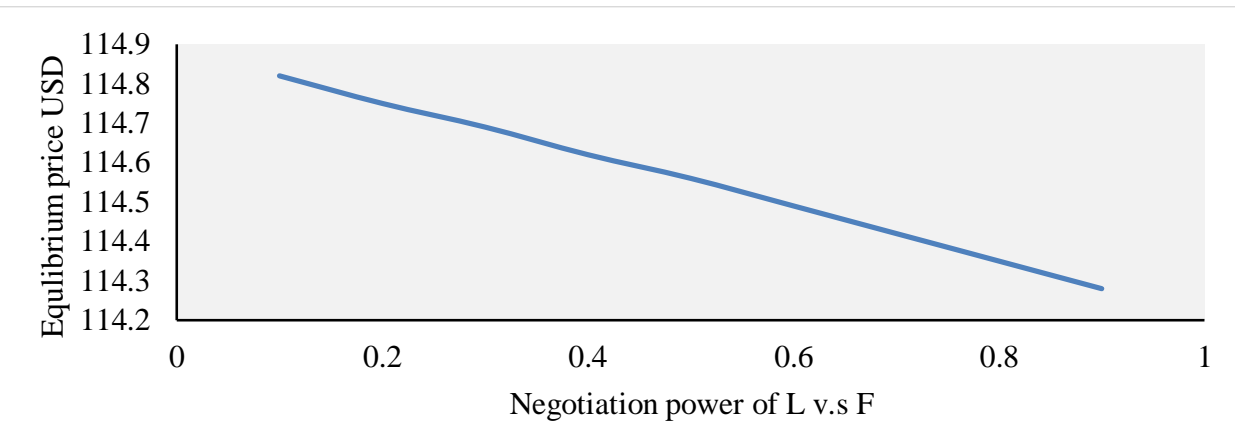

Fig 3. Changes in the equilibrium price in relation to the bargaining power of the domestic company against the foreign company

These results indicate that the bargaining game between domestic and foreign companies cannot affect the equilibrium price between the government and the established company by the domestic company and the license of the foreign company. If the government seeks to legislate how to choose foreign or local companies, it should consider such characteristics as market share and internal profitability of the companies and it should not interfere in the bargaining game between them.

\section{Conclusion}

The model proposed in the present study was implemented to price a drug for the treatment of thalassemia, and also to determine not only the modified price of the drug but also the parameters of the foreign company license. We also compared the results of the proposed model with common royalty rate 


\section{IJCIEOM}

International Joint Conference on Industrial Engineering and Operations Management- ABEPRO-ADINGOR-IISE-AIMASEM (IJCIEOM 2020)

in the PSC. The results showed that the assumption of equal negotiation power distorts the results from the common royalty rate; but when more bargaining power is considered for the government, as the legislator, the results of the proposed mechanism more resemble the conventional approaches. Furthermore, our findings showed that the results of cooperation are very sensitive toward the bargaining power of the government compared to that of the cooperative firm. Although using equal negotiation power for partners emphasizes strongly on the full partnership style, it might be different from the real-world problems. Hence, more detailed studies are required for identifying the relative negotiation power of the involved partners in the considered game which is proposed for future studies.

\section{References}

[CSANÁDI, M., KALÓ, Z., PRINS, C. P., GRÉLINGER, E., KISS, A. M., FRICKE, F.-U., FUKSA, L., TESAR, T., MANOVA, M. \& LORENZOVICI, L. 2018. The implications of external price referencing on pharmaceutical list prices in Europe. Health Policy and Technology, 7, 243-250.

HOSSEINI-MOTLAGH, S.-M., GOVINDAN, K., NEMATOLLAHI, M. \& JOKAR, A. 2019. An adjustable bi-level wholesale price contract for coordinating a supply chain under scenario-based stochastic demand. International Journal of Production Economics, 214, 175-195.

IMRAN, M., KANG, C. \& RAMZAN, M. B. 2018. Medicine supply chain model for an integrated healthcare system with uncertain product complaints. Journal of Manufacturing Systems, 46, 1328.

JABARZARE, N. \& RASTI-BARZOKI, M. 2019. A game theoretic approach for pricing and determining quality level through coordination contracts in a dual-channel supply chain including manufacturer and packaging company. International Journal of Production Economics, 107480.

KHODABAKHSHI, A., MASHREGHI, H. \& EMAMI, S. Coordination of a Three-echelon PharmaSupply Chain with Corporate Social Responsibility Under Spanning and Pair-wise Revenue Sharing Contracts. 2019 15th Iran International Industrial Engineering Conference (IIIEC), 2019. IEEE, 223-230.

NATIONAL CENTER FOR HEALTH, S. 2016. Health, United States. Health, United States, 2015: With Special Feature on Racial and Ethnic Health Disparities. Hyattsville (MD): National Center for Health Statistics (US).

NEMATOLLAHI, M., HOSSEINI-MOTLAGH, S.-M. \& HEYDARI, J. 2017. Economic and social collaborative decision-making on visit interval and service level in a two-echelon pharmaceutical supply chain. Journal of cleaner production, 142, 3956-3969.

SHAH, N. 2004. Pharmaceutical supply chains: key issues and strategies for optimisation. Computers \& chemical engineering, 28, 929-941.

TALEIZADEH, A. A., HAJI-SAMI, E. \& NOORI-DARYAN, M. 2019. A robust optimization model for coordinating pharmaceutical reverse supply chains under return strategies. Annals of Operations Research, 1-22.

VOGLER, S. \& MARTIKAINEN, J. E. 2015. Pharmaceutical pricing in Europe. Pharmaceutical prices in the 21 st century. Springer.

WERAIKAT, D., ZANJANI, M. K. \& LEHOUX, N. 2016. Two-echelon pharmaceutical reverse supply chain coordination with customers incentives. International Journal of Production Economics, 176, 41-52.

YOON, J., ROSALES, C. \& TALLURI, S. 2018. Inter-firm partnerships-strategic alliances in the pharmaceutical industry. International Journal of Production Research, 56, 862-881.

ZAHAROFF, H. G. 2004. Setting values and royalty rates for medical and life science businesses. JOURNAL OF BIOLAW AND BUSINESS, 7, 07-09. 